\title{
A Participatory Model of the Paradox of Primary Care
}

\author{
Academic Autbors \\ Laura Homa, PbD \\ Jobnie Rose, $M D, P b D$ \\ Peter S. Hovmand, PbD \\ Sarab T. Cherng, MPH \\ Rick L. Riolo, PbD \\ Alison Kraus, MSW \\ Anindita Biswas, MA, MPH \\ Kelly Burgess \\ Heide Aungst, MA \\ Kurt C. Stange, $M D, P b D$ \\ Patient, Caregiver, and Clinician \\ Autbors
}

Kalanthe Brown

Margaret Brooks-Terry, PbD

Ellen Dec

Brigid Jackson

Jules Gilliam

George E. Kikano, MD

Ann Reichsman, MD

Debbie Schaadt

Jamie Hilfer

Christine Ticknor, $\mathrm{PbD}$

Carl V. Tyler, MD

Anna Van der Meulen

Heather Ways, MD

Richard F. Weinberger, MD

Christine Williams, RN, FNP

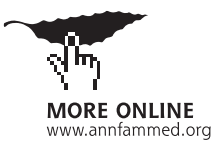

Conflicts of interest: authors report none.

\section{CORRESPONDING AUTHOR}

Kurt C. Stange, MD, PhD

Department of Family Medicine \& Community Health

Case Western Reserve University

11000 Cedar Ave, Suite 402

Cleveland, OH 44106-3069

kcs@case.edu

\begin{abstract}
PURPOSE The paradox of primary care is the observation that primary care is associated with apparently low levels of evidence-based care for individual diseases, but systems based on primary care have healthier populations, use fewer resources, and have less health inequality. The purpose of this article is to explore, from a complex systems perspective, mechanisms that might account for the effects of primary care beyond disease-specific care.
\end{abstract}

METHODS In an 8-session, participatory group model-building process, patient, caregiver, and primary care clinician community stakeholders worked with academic investigators to develop and refine an agent-based computer simulation model to test hypotheses about mechanisms by which features of primary care could affect health and health equity.

RESULTS In the resulting model, patients are at risk for acute illness, acute lifechanging illness, chronic illness, and mental illness. Patients have changeable health behaviors and care-seeking tendencies that relate to their living in advantaged or disadvantaged neighborhoods. There are 2 types of care available to patients: primary and specialty. Primary care in the model is less effective than specialty care in treating single diseases, but it has the ability to treat multiple diseases at once. Primary care also can provide disease prevention visits, help patients improve their health behaviors, refer to specialty care, and develop relationships with patients that cause them to lower their threshold for seeking care. In a model run with primary care features turned off, primary care patients have poorer health. In a model run with all primary care features turned on, their conjoint effect leads to better population health for patients who seek primary care, with the primary care effect being particularly pronounced for patients who are disadvantaged and patients with multiple chronic conditions. Primary care leads to more total health care visits that are due to more disease prevention visits, but there are reduced illness visits among people in disadvantaged neighborhoods. Supplemental appendices provide a working version of the model and worksheets that allow readers to run their own experiments that vary model parameters.

CONCLUSION This simulation model provides insights into possible mechanisms for the paradox of primary care and shows how participatory group model building can be used to evaluate hypotheses about the behavior of such complex systems as primary health care and population health.

Ann Fam Med 2015;13:456-465. doi: 10.1370/afm.1841.

\section{INTRODUCTION}

M ultiple studies have found that primary care is associated with poorer quality care for individual diseases than is care provided by clinicians focused primarily on those diseases. ${ }^{1-6}$ Yet, other evidence shows that systems based on primary care have better quality of care, better population health, greater equity, and lower cost. ${ }^{7-11}$ This discrepancy between apparently poor disease-specific care and advantageous outcomes at the level of the whole person and system has been called the paradox of primary care. ${ }^{12}$ Primary care is thought to be particularly important for disadvantaged populations and for people with multiple chronic conditions. ${ }^{13-15}$

Thus, it appears the complex interaction of primary care features can lead to emergent properties ${ }^{16,17}$ that provide value beyond disease-specific 
care. These features have been called the tenets of primary care, ${ }^{10,18-21}$ and include the following:

- Accessibility as the first contact with the health care system

- Accountability for addressing a great majority of personal health care needs (comprehensiveness)

- Coordination of care across settings and integration of care for acute and (often multiple) chronic illnesses, mental health, and prevention, guiding access to more narrowly focused care when needed

- Sustained partnership and personal relationships over time with patients known in the context of family and community

Management of specific diseases is far easier to conceptualize and measure than is the value added by the complex interaction of primary care's elements. During a time of rapid health system change, it is critical to understand the complex mechanisms of primary care that appear to provide its added value ${ }^{22-26}$ so that efforts to incentivize and improve the quality of (disease) care do not unintentionally diminish the effects of primary care that do not relate solely to the care of individual diseases. ${ }^{22-26}$

Conceptualizing primary care as a complex system ${ }^{17,27-29}$ can be helpful in overcoming the pitfalls of a simplistic, linear, reductionist understanding that cannot account for the emergent properties identified in the paradox of primary care. ${ }^{30}$ Computational simulation modeling can be a helpful tool for developing and testing hypotheses about how emergent properties might happen in complex systems. ${ }^{31}$ In particular, agent-based models, which specify the characteristics of people and their environment and which examine outcomes emerging from agent-agent-environment interactions over time are well-suited to understanding the complex phenomena of health care and health. ${ }^{32,33}$

Recently, principles from community-based participatory research ${ }^{34-36}$ have been used to engage stakeholders, with deep personal knowledge of the phenomenon under study, to work with scientists to develop, refine, and use models to test relevant hypotheses. ${ }^{38,39}$ These participatory group model-building methods, ${ }_{1}^{30,39,40}$ however, have not been applied to the development of agent-based models. ${ }^{41}$

We therefore set out to engage a team of academicians and community-based patients, caregivers, and primary care clinicians in a participatory process of developing an agent-based model of the paradox of primary care and in using the evolving model to test hypotheses about possible mechanisms by which primary care might affect population health and equity. Our purpose was not to compare specialty care with primary care, but to elucidate possible mechanisms for the effects of primary care beyond disease care.

\section{METHODS}

Beginning with a practice-based research network serving disadvantaged populations in Cleveland, Ohio the Safety Net Providers' Strategic Alliance, ${ }^{42}$ we conducted focus groups and individual interviews with patients, caregivers, and primary care clinicians to begin to identify features of primary care that might be important in addition to disease-specific care. We oversampled patients with multiple chronic conditions and expanded the initial sampling frame to maximize diversity in age, sex, socioeconomic status, and experience with primary and specialty care; and we sought clinicians from different community practice and health care system settings. From the focus groups and interviews, we selected a maximum diversity sample to participate in group model-building sessions.

These group model-building participants met approximately monthly for 8, 2-hour sessions to develop hypotheses and conceptual models of how people become ill and seek health care, as well as how health care, particularly primary care, affects health. Between sessions, these conceptual models were operationalized by programming an agent-based computer model using the NetLogo public domain software. ${ }^{43}$ Each model iteration was shared with the group at the following session and interactively refined over time. The content of the group's 8 sessions is outlined in Supplemental Appendix 1, available at http://www. annfammed.org/content/13/5/456/suppl/DC1.

Below we describe 2 different runs using the final model from this process. We begin with results from a base model with primary care features turned off, and then we show a more fully developed model that simulates what happens when patients receive components of primary care hypothesized by the group modelbuilding participants to provide added value. We examine model outputs of population health, health equity, and number of visits, and we examine the effects in advantaged and disadvantaged neighborhoods and for people with multiple chronic conditions. ${ }^{44}$

As appendices, we provide detailed technical summary of the model (Supplemental Appendix 2), the computer model (Supplemental Appendix 3) and instructions for downloading the free NetLogo software to run it (Supplemental Appendix 4), and worksheets for performing prespecified and user-initiated experiments, to allow readers to test their own hypotheses (Supplemental Appendix 5). All supplemental appendices are available at http://www.annfammed.org/content/13/5/456/suppl/DC1.

\section{RESULTS}

The participatory group model-building process was successful in engaging 8 female and 1 male patients 
and caregivers (often with multiple roles) with a variety of medical conditions, and 3 female and 3 male clinicians ( 5 family physicians and 1 nurse practitioner) in working with academicians to develop, refine, and test hypotheses with an agent-based model. In this process, they shared their experience as patients, caregivers, clinicians, health care administrators, etc, focusing on articulating simple methods to operationalize the mechanisms by which primary care operates.

\section{Description of Model Elements}

To be comprehensible and transparent, we created as simple a model as possible to operationalize health, illness, health care, and various primary care mechanisms. The model includes 3 types of agents: patients, primary care clinicians, and specialty clinicians. Below we give a brief description of the characteristics and actions of each.

\section{Patients}

Patients are characterized by the following traits:

- Health behaviors, which affect the probability of contracting an illness

- Care-seeking threshold-how much of a decline in health patients must suffer before seeking care for an illness

- Preference for care-either primary or specialty care (does not change over time)

- A patient's health, represented by a number between 0 and 1 (with 1 being perfect health), which changes when patients contract or recover from an illness

Patients are at risk for acquiring 4 different types of diseases: acute, acute life-changing, chronic, and mental illness, as shown in Supplemental Appendix 2. Disease burdens differ based on their initial effect on a patient's health and on the type of treatment delivered. Patients' probability of contracting each type of disease depends on their health behavior and other risk factors.

Patients can suffer from multiple diseases at once. They seek care with their chosen clinician once the combined effects of their illnesses have caused their health to decrease below their individual care-seeking threshold.

\section{Specialty Clinicians}

Specialty-seeking patients visit a specialty clinician only when they are ill. Specialty clinicians focus their treatment on the disease that is having the biggest effect on patients' health.

\section{Primary Care Clinicians}

Primary care clinicians treat multiple illnesses in a single visit, but in the model runs shown in this article, they are less effective than specialists in treating any particular disease. Primary care clinicians also potentially have the ability to do the following:

- Help patients improve their health behavior, which will decrease their probability of contracting illness

- Develop a relationship with patients which, over time, will cause patients to reduce their care-seeking threshold and seek care earlier in an illness

- Refer a patient to specialty care for treatment, if treatment by a specialist will provide a greater health benefit than treatment by primary care

Primary care-seeking patients visit a primary care clinician when they are ill, but they also have the option of making regular check-up visits. At these check-up visits, health problems may be identified and treated even if they have not lowered health below the patient's care-seeking threshold.

A summary of the main mechanisms of the model is shown in Figure 1.

\section{The NetLogo Model}

The full details of implementation of the model in NetLogo are provided in Supplemental Appendix 2. Supplemental Appendix 6 shows screen shots of the model. "Sliders" allow users to control the input variables for each type of agent, and a graphical interface

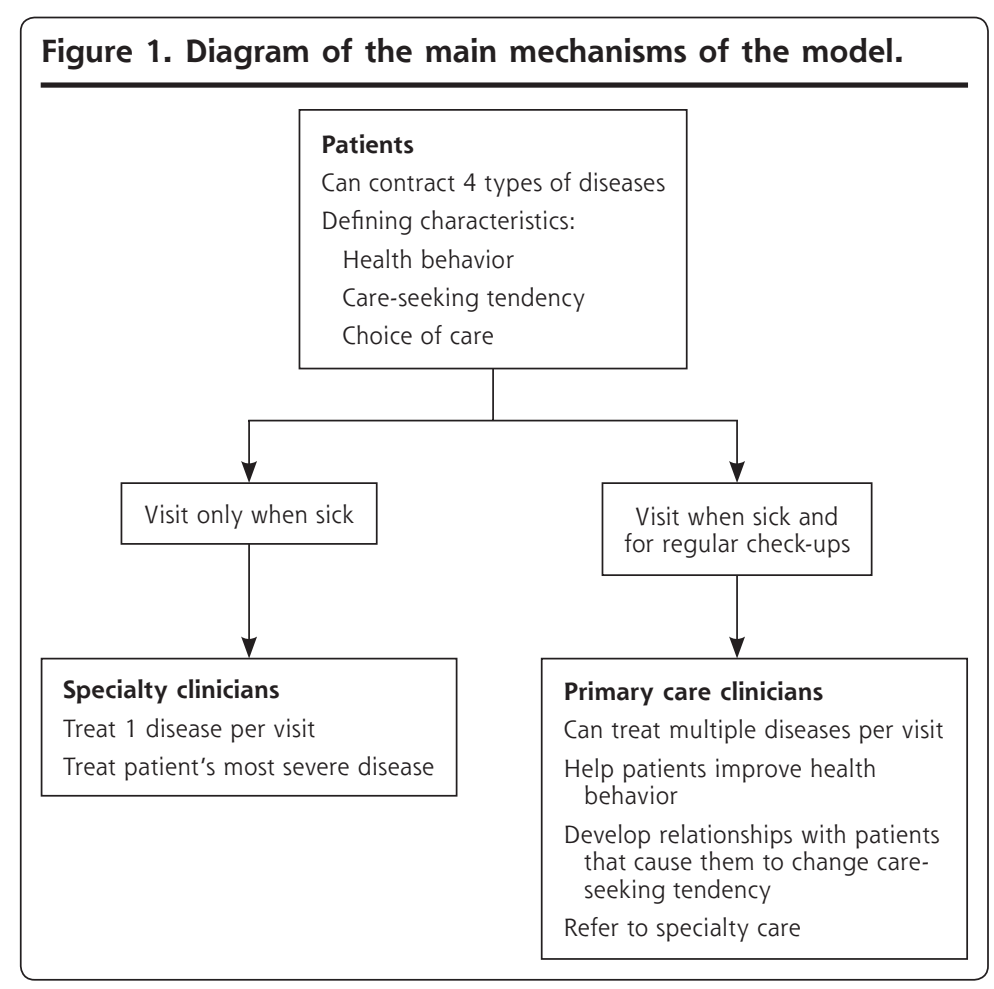


shows agents in the 4 neighborhoods (Supplemental Appendix 7). Supplemental Appendix 8 shows sample health output graphs. Variables that define the specific characteristics of each type of agent, allowing the model user to conduct various experiments, are listed in Table 1. The model contains 2,000 patients, 1 primary care clinician, and 1 specialty clinician. We split patients evenly into 2 "neighborhoods," labeled A and B. Patients in each neighborhood have their own userdefined health behaviors and care-seeking tendency. Within these neighborhoods, patients are split evenly between primary care-seekers and specialty-seekers. Each time step in the model represents 1 week $_{i}$ the model runs for 2,500 time steps, or about 48 years.

As the model runs, it tracks the following outputs for each neighborhood and each type of care-seeker:

- Average health of all patients

- Average health of patients with 3 or more nonacute diseases

- Average number of total clinician visits per patient

- Average number of sick visits that occurred because patients' health declined below their care-seeking threshold

For primary care-seeking patients, the model output tracks the number of visits that resulted in referrals to specialty care.

\section{Results From 2 NetLogo Simulations}

We ran a number of different experiments to test how the average population health and average number of clinician visits per patient were affected when we changed the primary care input variables one at a time. The specific values for each of the input variables for each experiment are included in the worksheets in Supplemental Appendix 5.

Below we will describe the results from experiments 1 , a simple base model, and experiment 6 , a model that includes multiple primary care mechanisms. (Experiments 2 to 5 add individual primary care mechanisms to the base model.)

In experiment 1, all mechanisms of primary care beyond disease care are turned off, meaning that primary care cannot help patients change their health behaviors or care-seeking tendencies and cannot refer to specialty care, and patients do not make regular wellcare visits to primary care. Furthermore, although primary care can treat multiple diseases per visit, it is less effective than specialty care in treating a single disease.

In experiment 6 , all the aforementioned attributes of primary care are turned on.

In each of these simulations, patients in neighborhood A have a low care-seeking threshold and average health behavior, whereas patients in neighborhood $\mathrm{B}$ have a high care-seeking threshold (and thus lower
Table 1. A List of the User-Controlled Inputs in the NetLogo Model For Each Type of Agent

\begin{tabular}{|c|c|}
\hline Type of Agent & User-Controlled Inputs \\
\hline \multirow[t]{2}{*}{ Patients } & Health behavior \\
\hline & Care-seeking tendency \\
\hline $\begin{array}{l}\text { Specialty } \\
\text { clinicians }\end{array}$ & $\begin{array}{l}\text { Effectiveness level, which determines the } \\
\text { amount of health lost to a single disease } \\
\text { they can restore }\end{array}$ \\
\hline \multirow[t]{5}{*}{$\begin{array}{l}\text { Primary care } \\
\text { clinicians }\end{array}$} & $\begin{array}{l}\text { Effectiveness level (across whatever illnesses } \\
\text { the patient has) }\end{array}$ \\
\hline & $\begin{array}{l}\text { Number of regular checkup visits per year that } \\
\text { primary care-seeking patients make }\end{array}$ \\
\hline & $\begin{array}{l}\text { Extent to which they can help patients improve } \\
\text { their health behavior }\end{array}$ \\
\hline & $\begin{array}{l}\text { Extent to which a primary care-seeking patient } \\
\text { will change their care-seeking tendency }\end{array}$ \\
\hline & Tendency to refer to specialty care \\
\hline
\end{tabular}

access to care) and poorer health behavior. Thus neighborhood A represents a relatively advantaged neighborhood and neighborhood B represents a relatively disadvantaged neighborhood.

Graphs from both experiments of the average health in each neighborhood for each type of careseeker are shown in Figure 2. In experiment 1, the health of primary care-seeking patients is worse than the health of specialty-seeking patients in both neighborhoods for the entirety of the model run. This finding is not surprising; in experiment 1 , although primary care treats multiple diseases in a visit, it is less effective than specialty in treating a single disease and does not offer any additional benefits.

In experiment 6 , the opposite result occurs-primary care-seekers have better average health in both neighborhoods. In this model, we see that the conjoint effect of multiple primary care features is able to compensate for its lesser disease-specific care.

The health of primary care patients increases more from experiment 1 to experiment 6 for patients in the disadvantaged than the advantaged neighborhood. As a result of their poor health behaviors, patients in neighborhood $\mathrm{B}$ are sick more often than those in neighborhood $\mathrm{A}_{\text {; }}$ additionally, because of their high care-seeking threshold, they tend to wait longer to seek care for an illness.

The primary care effect is greater for people with multiple chronic conditions, as seen in Figure 3, which shows the average health of patients with 3 or more nonacute diseases in each neighborhood for both experiments. In experiment 1 , the health of primary care-seeking patients is lower than the health of specialty care-seeking patients, whereas in experiment 6 , the opposite is true. This finding is similar to what was observed in the overall average health of each neighborhood, but the effect is more pronounced. The 
Figure 2. Average health for people receiving primary or special care in 2 neighborhoods.

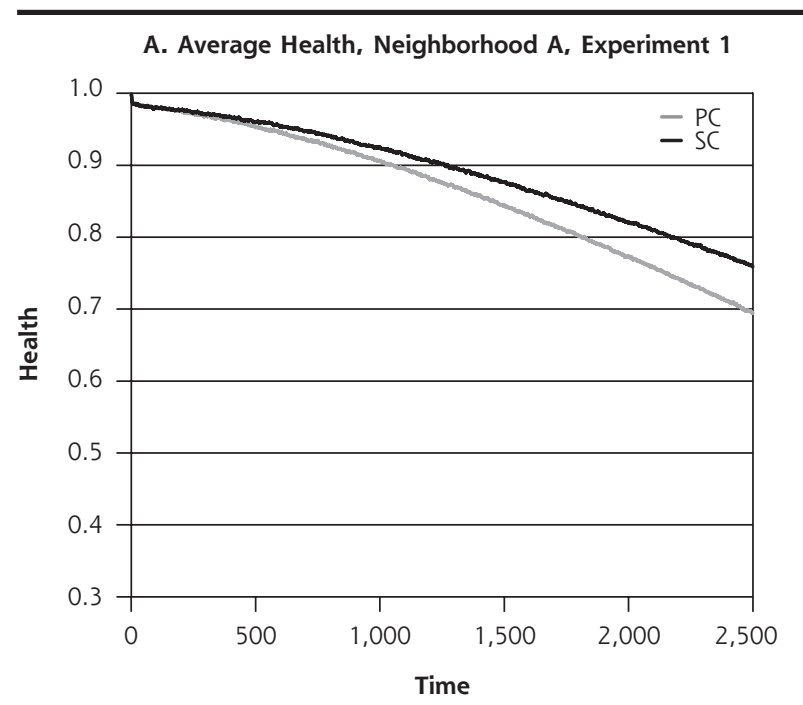

B. Average Health, Neighborhood B, Experiment 1

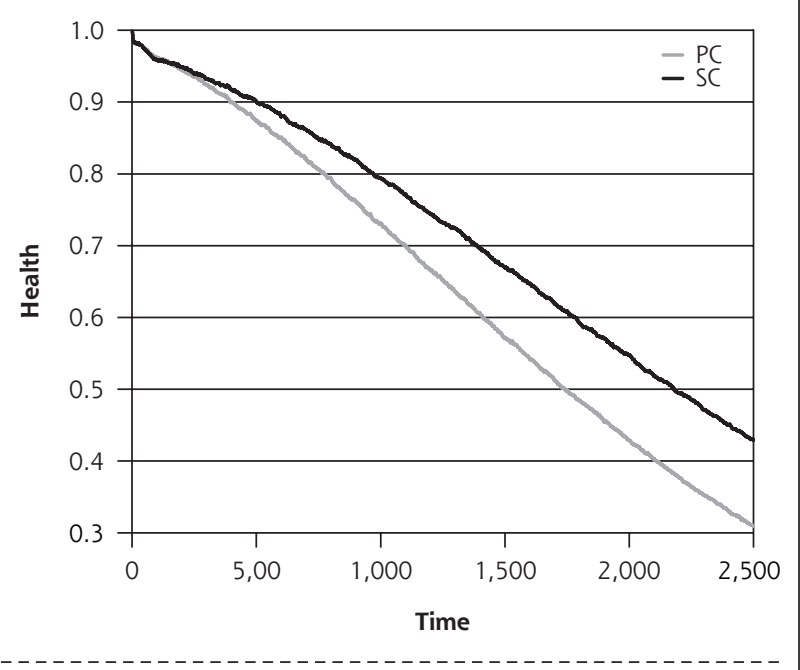

C. Average Health, Neighborhood A, Experiment 6

D. Average Health, Neighborhood B, Experiment 6
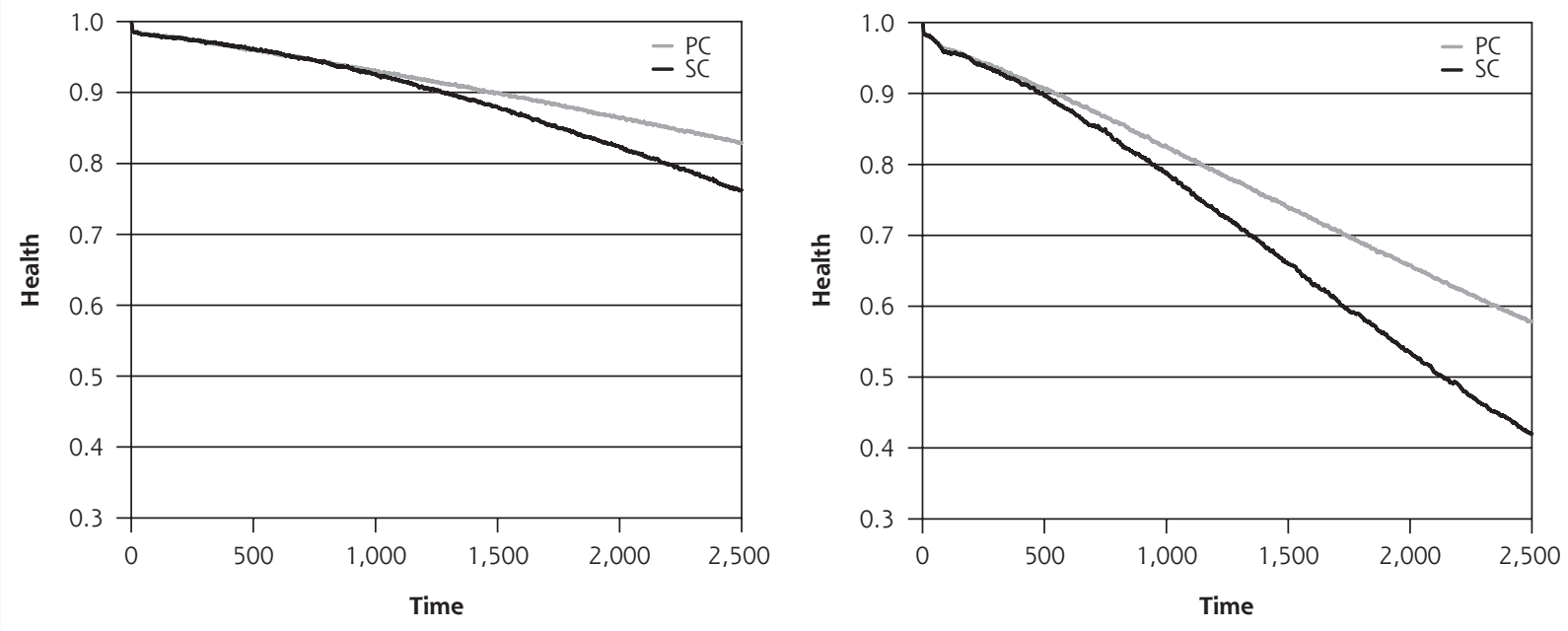

$\mathrm{PC}=$ primary care; $\mathrm{SC}=$ specialty care.

The top row shows average health of patients (represented by a number between 0 and 1 with 1 being perfect health) in neighborhood A (left) and neighborhood B (right) for experiment 1 (no primary care features turned on), and the bottom row shows the same result for experiment 6 (all primary care features turned on). The black line in each graph shows the average health of specialty care seekers in each neighborhood, and the gray line shows the health of primary care seekers. The $x$ axis is time (in weeks) and the $y$ axis is health.

difference in health between primary and specialty care patients in experiment 6 is greater for patients in neighborhood B (the disadvantaged neighborhood). This difference is greater for patients in neighborhood B with multiple diseases than for the overall neighborhood, which suggests that the primary care benefit in the model is greatest for disadvantaged patients with multiple diseases.

Figure 4 shows the average number of clinician visits. In experiment 1 , primary and specialty care seekers have essentially the same number of visits, because in this base model both types of patients seek care only when they are ill and have similar rates of illness. As a result of their poor health behaviors, patients in neighborhood $\mathrm{B}$ are more likely to develop illnesses and therefore have more visits than patients in neighborhood A.

In experiment 6 , with all the primary care features activated, the number of visits for primary care seekers increases because of regular preventive visits. Unlike experiment 1, primary care patients in neighborhood A have more visits than primary care patients in neighborhood B. In experiment 6 , primary care patients decrease their care-seeking threshold over time as they 
develop a relationship with the primary care clinician, which causes their number of visits to increase, particularly for neighborhood A, in which patients initially have a relatively low care-seeking threshold.

Figure 5 shows the average number of sick visits for each neighborhood for each type of patient for both experiments. In experiment 1 , the number of sick visits is the same for primary care and specialty patients.
The results are more interesting in experiment 6 , with the number of sick visits for primary care patients in neighborhood $\mathrm{A}$ increasing from experiment 1. This result is not because the primary care patients in neighborhood $\mathrm{A}$ are sick more often in experiment $6_{;}$in fact, they contract fewer illnesses because their health behaviors are improved from experiment 1 . This change is due to patients in neighborhood A decreas-

Figure 3. Average health for people with or more ongoing health conditions, receiving primary or specialty care in 2 neighborhoods.
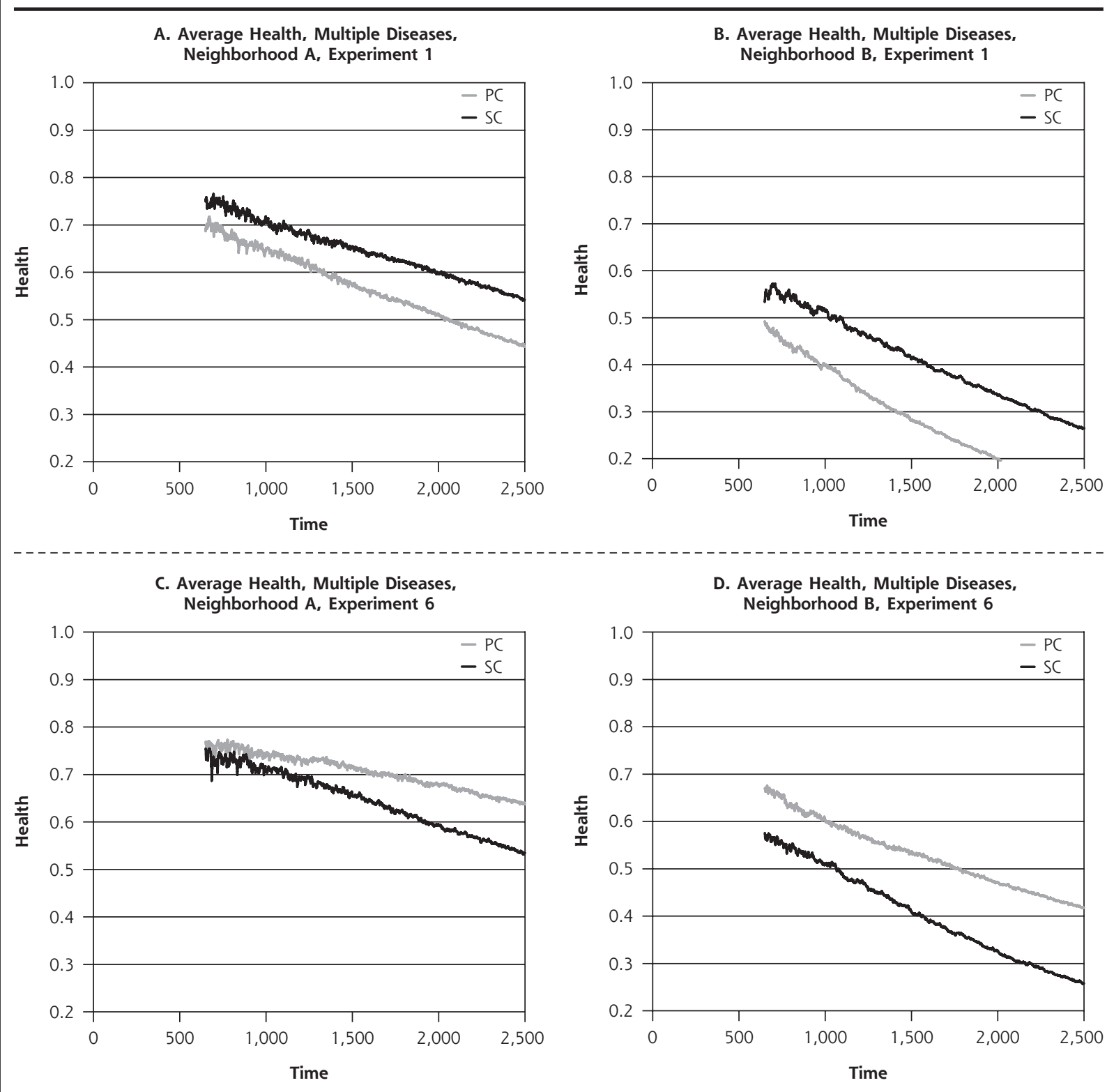

$\mathrm{PC}=$ primary care; $\mathrm{SC}=$ specialty care

The top row shows average health of patients (represented by a number between 0 and 1 with 1 being perfect health) with 3 or more nonacute diseases in neighborhood A (left) and neighborhood B (right) for experiment 1 (no primary care features turned on), and the bottom row shows the same result for experiment 6 (all primary care features turned on). The black line in each graph shows the average health for specialty care seekers in each neighborhood, and the gray line shows the health for primary care seekers. On the $x$ axis is time (in weeks). Note that the results are graphed only after the model has run long enough for a sufficient number of patients who have accumulated multiple diseases. 
Figure 4. Average number of visits for people receiving primary or specialty care in 2 neighborhoods.

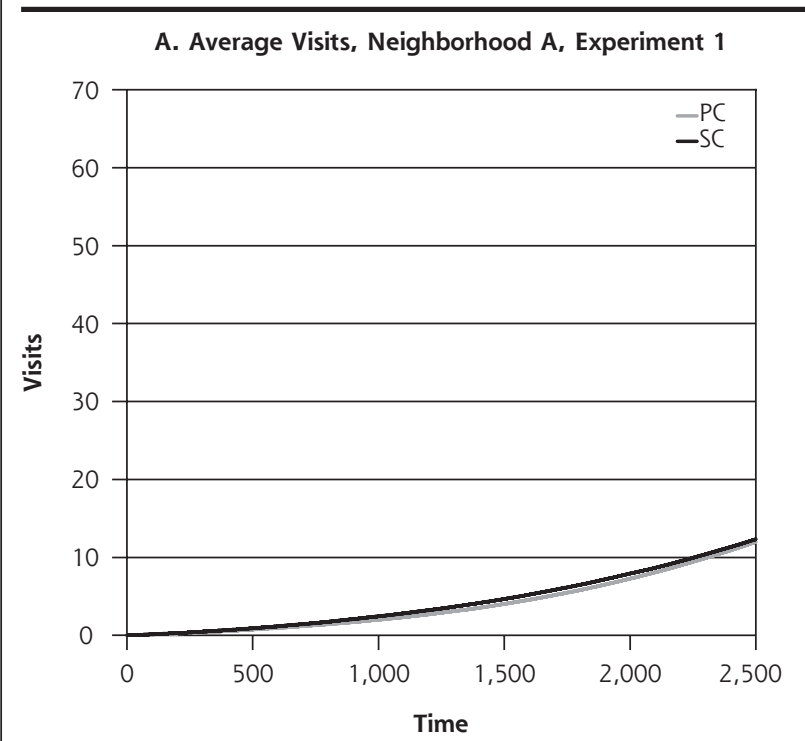

B. Average Visits, Neighborhood B, Experiment 1

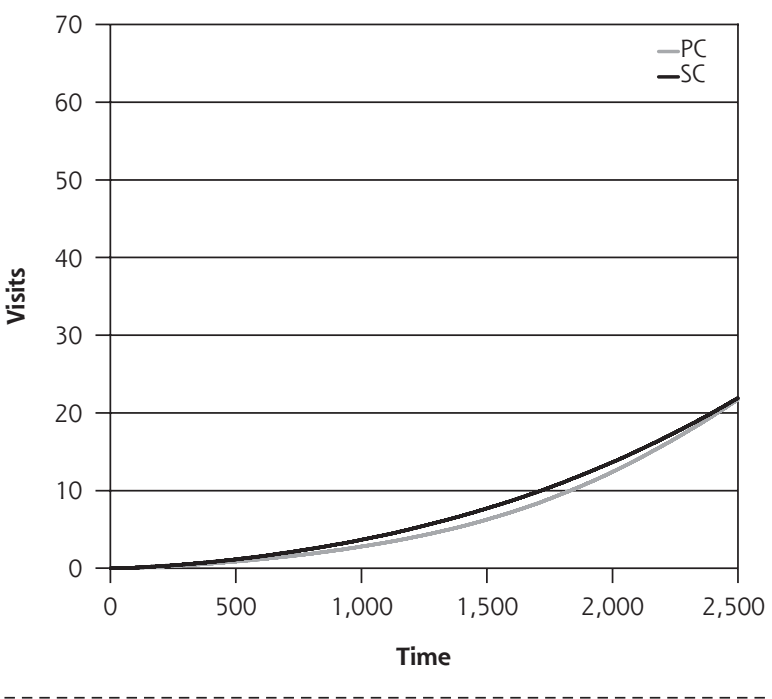

C. Average Visits, Neighborhood A, Experiment 6

D. Average Visits, Neighborhood B, Experiment 6
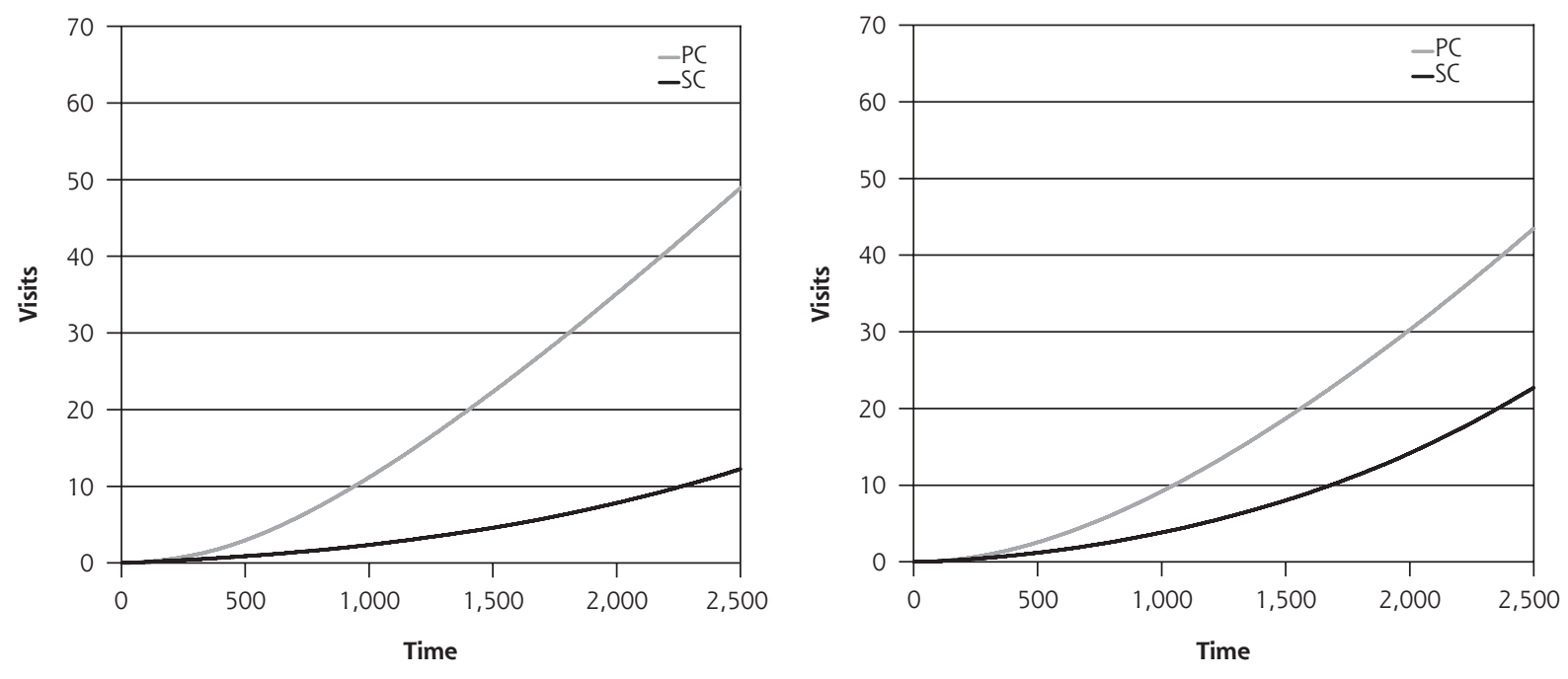

$\mathrm{PC}=$ primary care; $\mathrm{SC}=$ specialty care

The top row shows average number of clinician visits for patients in neighborhood A (left) and neighborhood B (right) for experiment 1 (no primary care features turned on), and the bottom row shows the same result for experiment 6 (all primary care features turned on). The black line in each graph shows the average clinician visits for specialty care seekers in each neighborhood, and the gray line shows the average clinician visits for primary care seekers. On the $\mathrm{x}$ axis is time (in weeks).

ing their care-seeking threshold as they develop a relationship with their primary care clinician.

In contrast, the number of sick visits for primary care patients in neighborhood B decreases from experiment 1 to experiment 6 . In experiment 6 , primary care patients in neighborhood $\mathrm{B}$ decrease their care-seeking threshold, which causes their number of sick visits to increase. At the same time, however, they improve their health behavior, which causes their number of illnesses, and subsequently their number of sick visits, to decrease. Because primary care patients in neighbor- hood B start with a higher care-seeking threshold than patients in neighborhood $\mathrm{A}$, the effect of health behavior change predominates in determining the number of sick visits for patients in neighborhood B. The overall effect is a reduction of sick visits in this disadvantaged neighborhood.

\section{DISCUSSION}

We were able to engage diverse patient, caregiver, clinician, and academic stakeholders in an iterative, 
Figure 5. Average number of sick visits for people receiving primary or specialty care in 2 neighborhoods.

A. Average Sick Visits, Neighborhood A, Experiment 1

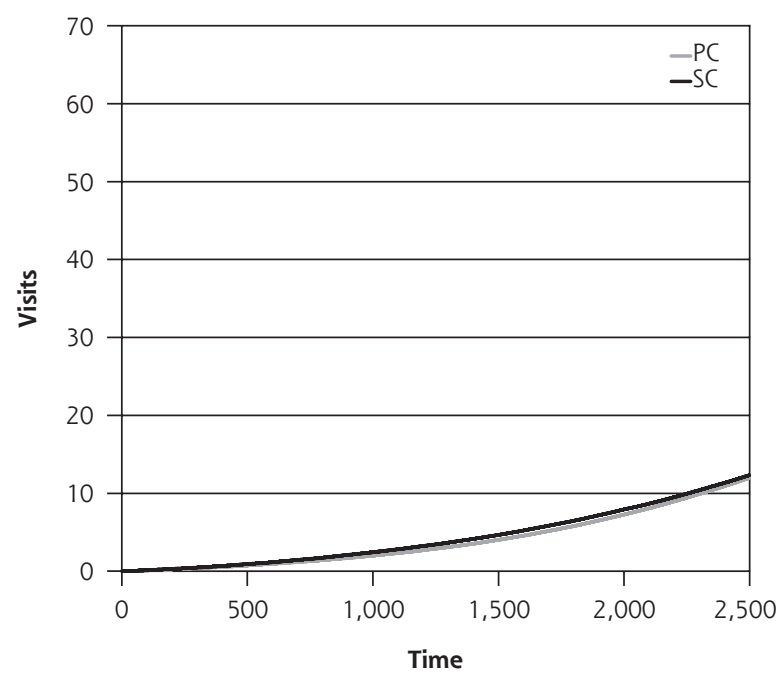

C. Average Sick Visits, Neighborhood A, Experiment 6

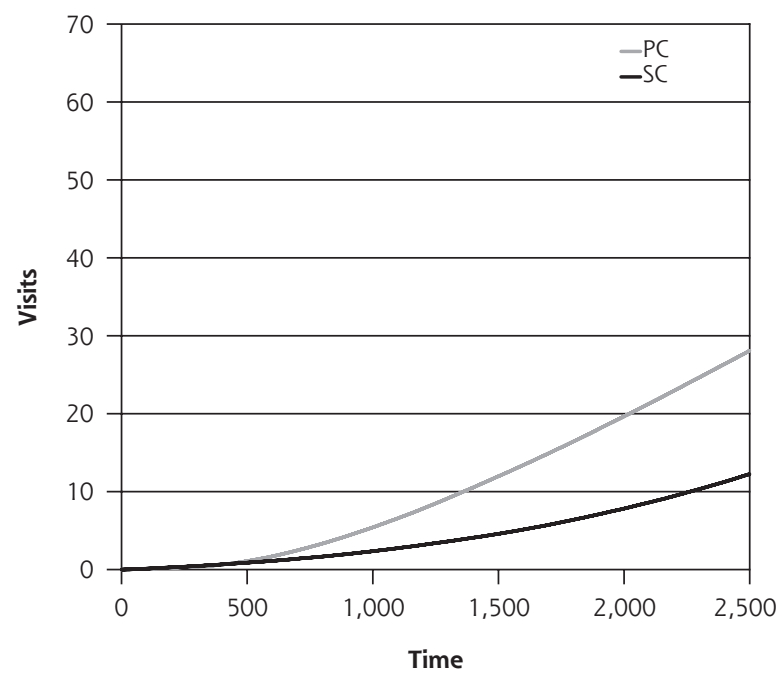

B. Average Sick Visits, Neighborhood B, Experiment 1

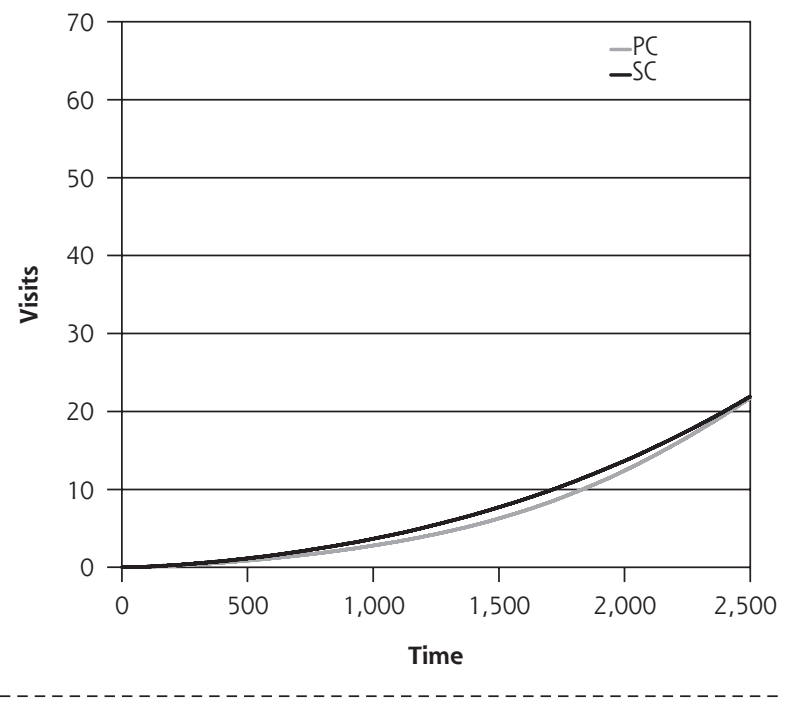

D. Average Visits, Neighborhood B, Experiment 6

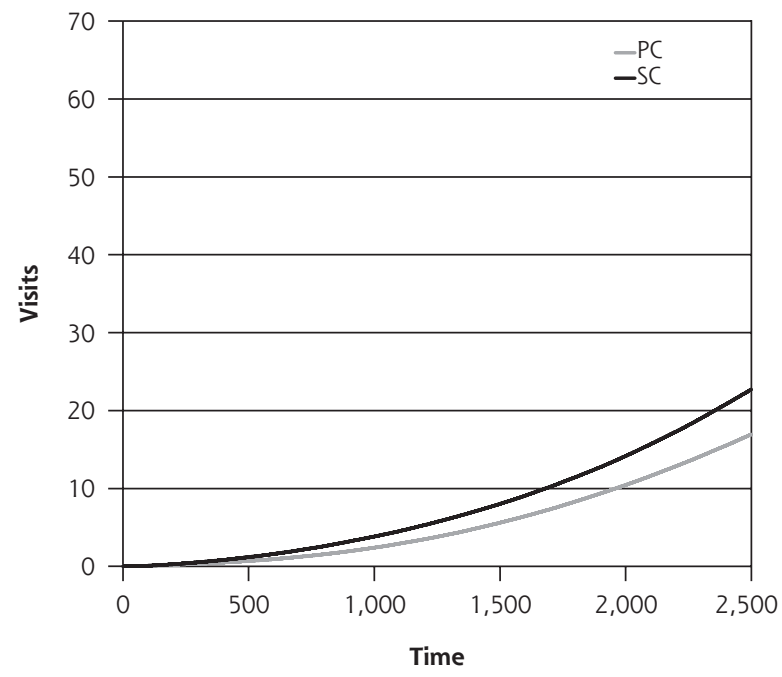

$\mathrm{PC}=$ primary care; $\mathrm{SC}=$ specialty care

The top row shows the average number of sick visits for patients in neighborhood A (left) and neighborhood B (right) from experiment 1 . The bottom row shows the same results for experiment 6 . In each graph, the black line tracks the average sick visits for specialty patients, and the gray line tracks this number for primary care patients.

participatory process to build an agent-based model. The model operationalizes in a simple but explicit way some of the key features of primary care and allows testing hypotheses about how different primary care mechanisms can combine to add value beyond disease treatment and how these mechanisms affect the health of different types of people. The model can be used to generate an understanding of (primary) health care as a complex system in which factors in addition to disease care can affect outcomes such as health, equity, and resource use.
The model shows possible mechanisms by which non-disease-specific aspects of primary care can produce the emergent properties that have been observed in epidemiological and ecological studies. ${ }^{45,46}$ The resulting understanding could help to overcome some of the reductionist biases ${ }^{4-49}$ that have resulted in measuring primary care quality based on 1 disease at a time, rather than assessing quality in ways that fully consider the complex conjoint effects of multiple mechanisms. ${ }^{27,47-49}$ Greater understanding of the complexity of primary care could be used to develop sys- 
tems to support care that is integrated, personalized, preventive, and of high value.

\section{Limitations}

The model incorporates the wisdom of diverse health care users and providers, but it is limited to primary care clinicians and patients in a single geographic area, as well as by many simplifying assumptions needed to make the model transparent and easy to describe and understand. Primary care involves the complex interaction of many other mechanisms than those proposed here. A group model-building team that included other viewpoints, such as disease specialists, would likely have come up with different parameters and ways to operationalize of primary care, some of which could equally well predict the paradox. The model's parameters reflect general stylized facts from the health and health care literature, but it is limited in not being based on empirical health services and outcome data. Development of a data-driven model remains an important area for future research.

In the meantime, the model allows users to develop and test hypotheses that would be difficult or impossible to test in the real world. We encourage readers to download the model, software, and worksheets from the appendices and to undertake their own experiments by developing their own hypotheses, varying the related model parameters, running the model, using the worksheets to keep track of the results, and reporting their findings in the Annals eLetter discussion related to this article (TRACK). The resulting insights can be used not only to develop more sophisticated models, but to guide empirical research and to advance more nuanced understanding of the value of primary care and the possible complex interactive mechanisms by which that value emerges over time.

To read or post commentaries in response to this article, see it online at http://www.annfammed.org/content/13/5/456.

Key words: decision modeling; economic models; statistical models

Submitted July 7, 2014; submitted, revised, May 19, 2015; accepted June 21, 2015.

Funding support: This research is funded by Contract Number 1IP2PI000216-01 from the Patient-Centered Outcomes Research Institute (PCORI). An earlier pilot study was supported by a grant from the Network on Inequalities, Complexity and Health (NICH), which is supported by the NIH Office of Behavioral and Social Science Research. . Dr Stange's time is supported in part by a Clinical Research Professorship from the American Cancer Society, and as a Scholar of The Institute for Integrative Health. This publication additionally was made possible by support from the Clinical and Translational Science Collaborative of Cleveland, UL1TR000439 from the National Center for Advancing Translational Sciences (NCATS) component of the National Institutes of Health and NIH roadmap for Medical Research.
Disclaimer: The contents of this article are solely the responsibility of the authors and do not necessarily represent the official views of the $\mathrm{NIH}$. All statements in this report, including its findings and conclusions, are solely those of the authors and do not necessarily represent the views of the Patient-Centered Outcomes Research Institute (PCORI), its Board of Governors or Methodology Committee.

Author affiliations: Department of Family Medicine and Community Health, Case Western Reserve University, Cleveland, Ohio (Homa, Rose, Biswas, Burgess, Aungst, Stange); System Dynamics Design Laboratory, George Warren Brown School of Social Work, Washington University, St Louis, Missouri (Hovmand, Kraus); Center for the Study of Complex Systems, University of Michigan, Ann Arbor, Michigan (Riolo); Cleveland, Ohio (Brown, Dec, Gilliam, Schaadt, Hilfer, Van der Meulen); Case Western Reserve University, Cleveland, Ohio (Brooks-Terrry, Ticknor); MetroHealth System, Cleveland, Ohio (Jackson); College of Medicine, Central Michigan University, Mount Pleasant, Michigan (Kikano); Neighborhood Family Practice, Cleveland, Ohio (Reichsman, Ways, Williams); Cleveland Clinic, Cleveland, Ohio (Tyler); Weinberger \& Vizy, LLC (Weinberger).

Acknowledgments: NICH members (http://sitemaker.umich.edu/nich/ network_members) and Robert Ferrer, MD, MPH, David Katerndahl, MD, and Carlos Jaén, MD, PhD, were vitally helpful in the NICH pilot, which provided important initial conceptualizations for this work.

Supplementary materials: Available at http://www.AnnFamMed. org/content/13/5/456/suppl/DC1/

\section{References}

1. Harrold LR, Field TS, Gurwitz JH. Knowledge, patterns of care, and outcomes of care for generalists and specialists. J Gen Intern Med. 1999;14(8):499-511.

2. Smetana GW, Landon BE, Bindman AB, et al. A comparison of outcomes resulting from generalist vs specialist care for a single discrete medical condition: a systematic review and methodologic critique. Arch Intern Med. 2007;167(1):10-20.

3. Shah BR, Hux JE, Laupacis A, Mdcm BZ, Austin PC, van Walraven C. Diabetic patients with prior specialist care have better glycaemic control than those with prior primary care. J Eval Clin Pract. 2005; 11(6):568-575.

4. McAlister FA, Majumdar SR, Eurich DT, Johnson JA. The effect of specialist care within the first year on subsequent outcomes in 24,232 adults with new-onset diabetes mellitus: population-based cohort study. Qual Saf Health Care. 2007;16(1):6-11.

5. Go AS, Rao RK, Dauterman KW, Massie BM. A systematic review of the effects of physician specialty on the treatment of coronary disease and heart failure in the United States. Am J Med. 2000;108(3): 216-226.

6. Backer V, Nepper-Christensen S, Nolte H. Quality of care in patients with asthma and rhinitis treated by respiratory specialists and primary care physicians: a 3-year randomized and prospective follow-up study. Ann Allergy Asthma Immunol. 2006;97(4):490-496.

7. Starfield B, Shi L, Macinko J. Contribution of primary care to health systems and health. Milbank Q. 2005;83(3):457-502.

8. Starfield B, Shi L, Grover A, Macinko J. The effects of specialist supply on populations' health: assessing the evidence. Health Aff (Millwood). 2005;(Suppl Web Exclusives):W5-97-W5-107.

9. Baicker K, Chandra A. Medicare spending, the physician workforce, and beneficiaries' quality of care. Health Aff (Millwood). 2004;W/4 (Suppl Web Exclusives):W4-184-97. http://content.healthaffairs.org/ cgi/reprint/hlthaff.w4.184v1? maxtoshow $=$ EHITS $=10$ \&hits $=10$ ERES ULTFORMAT = Eauthor $1=$ baickerEandorexactfulltext $=$ and ssearchid $=1$ EFIRSTINDEX=0\&resourcetype $=$ HWCIT. Accessed July 6, 2010 . 
10. Donaldson MS, Lohr KN, Vanselow NA, eds. Primary Care: America's Health in a New Era. Washington, D.C.: National Academy Press; 1996.

11. Macinko J, Starfield B, Shi L. Quantifying the health benefits of primary care physician supply in the United States. Int J Health Serv. 2007;37(1):111-126.

12. Stange KC, Ferrer RL. The paradox of primary care. Ann Fam Med. 2009;7(4):293-299.

13. Lewin S, Lavis JN, Oxman AD, et al. Supporting the delivery of cost-effective interventions in primary health-care systems in lowincome and middle-income countries: an overview of systematic reviews. Lancet. 2008;372(9642):928-939.

14. Fortin $M$, Soubhi $H$, Hudon $C$, Bayliss EA, van den Akker M. Multimorbidity's many challenges. BMJ. 2007;334(7602):1016-1017.

15. Starfield B. Primary care and equity in health: the importance to effectiveness and equity of responsiveness to people's needs. Humanity Soc. 2009;33:56-73.

16. Sturmberg JP, Martin CM, Moes MM. Health at the center of health systems reform: how philosophy can inform policy. Perspect Biol Med. 2010;53(3):341-356

17. Sweeney K. Complexity in Primary Care. Oxon, UK: Radcliffe Publish ing Ltd; 2006.

18. Starfield B. Primary Care: Balancing Health Needs, Services, and Technology. Rev. ed. ed. New York, NY: Oxford University Press; 1998.

19. McWhinney IR, Freeman T. Textbook of Family Medicine. 3rd ed. New York, NY: Oxford University Press; 2009.

20. Stange KC, Nutting PA, Miller WL, et al. Defining and measuring the patient-centered medical home. J Gen Intern Med. 2010;25(6): 601-612.

21. Stange $K C$, Jaén $C R$, Flocke $S A$, Miller WL, Crabtree BF, Zyzanski SJ. The value of a family physician. J Fam Pract. 1998;46(5):363-368.

22. Marshall MN, Romano PS, Davies HT. How do we maximize the impact of the public reporting of quality of care? Int J Qual Health Care. 2004;16(Suppl 1):i57-i63.

23. Casalino LP. The unintended consequences of measuring quality on the quality of medical care. N Engl J Med. 1999;341(15):1147-1150.

24. McGlynn EA. Intended and unintended consequences: what should we really worry about? Med Care. 2007;45(1):3-5.

25. De Maeseneer J, van Weel C, Egilman D, Mfenyana K, Kaufman A, Sewankambo N. Strengthening primary care: addressing the disparity between vertical and horizontal investment. $\mathrm{Br} J$ Gen Pract. 2008;58(546):3-4.

26. Stange KC. The paradox of the parts and the whole in understanding and improving general practice. Int J Qual Health Care. 2002;14 (4):267-268.

27. Heath I, Rubenstein A, Stange KC, van Driel M. Quality in primary health care: a multidimensional approach to complexity BMJ. 2009; 338:b1242.

28. Sturmberg JP. Systems and complexity thinking in general practice. Part 2: application in primary care research. Aust Fam Physician. 2007;36(4):273-275.

29. Sturmberg JP. Systems and complexity thinking in general practice: part 1 - clinical application. Aust Fam Physician. 2007;36(3):170-173.
30. Rose J, Riolo R, Hovmand P, et al. Modeling the Paradox of Primary Care. In: Martin C, Sturmberg J, eds. Handbook on Systems and Complexity in Health. New York, NY: Springer Press; 2013:815-825.

31. Parunak HVD, Savit R, Riolo RL. Agent-based modeling vs. equation-based modeling: a case study and users' guide. Proceedings of Multi-agent Systems and Agent-based Simulation. 1998. http:// www.citeulike.org/user/lavinp/article/7681604.

32. Bankes SC. Agent-based modeling: a revolution? Proc Natl Acad Sci U S A. 2002;99(Suppl 3):7199-7200.

33. Gilbert N. Agent-Based Models. London: Sage Publications; 2007.

34. Israel BA, Eng E, Schulz AJ, Parker EA. Methods for Community-Based Participatory Research for Health. 2nd ed. Hoboken, NJ: Wiley; 2012.

35. Macaulay AC, Commanda LE, Freeman WL, et al.; North American Primary Care Research Group. Participatory research maximises community and lay involvement. BMJ. 1999;319(7212):774-778.

36. Macaulay AC, Nutting PA. Moving the frontiers forward: incorporating community-based participatory research into practice-based research networks. Ann Fam Med. 2006;4(1):4-7.

37. Hovmand PS, Brennan L, Chalise N. Whose model is it anyway? Paper presented at: The 29th International Conference of the System Dynamics SocietyJuly 25 - 29, 2011; Washington, DC.

38. Hovand PS. Community Based System Dynamics. New York, NY: Springer; 2014.

39. Hovmand PS, Etiënne AJA, Rouwette E, et al. Scriptapedia: A Handbook of Scripts for Developing Structured Group Model Building Sessions. Paper presented at: The 29th International Conference of the System Dynamics SocietyJuly 25-29, 2011.

40. Rouwette E, Vennix JAM. Mullekom Tv. Group model building effectiveness: A review of assessment studies. Syst Dyn Rev. 2006; 18(1):5-45.

41. Hovmand PS, Etiënne AJA, Rouwette E, et al. Scriptapedia 3.04. 2011. http://www.systemdynamics.org/other_resources.htm/scriptapedia. Accessed November 23, 2014.

42. Practice-Based Research Network Shared Resource. Safety Net Providers' Strategic Alliance. https://sites.google.com/a/case.edu/snpsa/ home. Accessed May 15, 2014.

43. NetLogo. Netlogo. http://ccl.northwestern.edu/netlogo/. Accessed April 14, 2014.

44. Bayliss EA, Bonds DE, Boyd CM, et al. Understanding the context of health for persons with multiple chronic conditions: moving from what is the matter to what matters. Ann Fam Med. 2014;12(3): 260-269.

45. Baicker K, Chandra A. Medicare spending, the physician workforce, and beneficiaries' quality of care. Health Aff (Millwood). 2004;(Suppl Web Exclusives):W/4-184-97.

46. Starfield B, Shi LY, Macinko J. Contribution of primary care to health systems and health. Milbank Q. 2005;83(3):457-502.

47. Stange KC. A science of connectedness. Ann Fam Med. 2009;7(5): 387-395.

48. Stange KC. The problem of fragmentation and the need for integrative solutions. Ann Fam Med. 2009;7(2):100-103.

49. Stange KC. Ways of knowing, learning, and developing. Ann Fam Med. 2010;8(1):4-10. 